\title{
Differential Changes in Bone Mineral Density of the Appendicular and Axial Skeleton with Aging
}

\author{
RELATIONSHIP TO SPINAL OSTEOPOROSIS
}

\author{
B. L. Riggs, H. W. Wahner, W. L. Dunn, R. B. Mazess, K. P. Offord, and \\ L. J. MeLton III, Endocrinology Research Unit, Division of Endocrinology/ \\ Metabolism and Internal Medicine, Section of Diagnostic Nuclear Medicine, and \\ Department of Medical Statistics and Epidemiology, Mayo Clinic and Mayo \\ Foundation, Rochester, Minnesota 55905; Department of Radiology, \\ University of Wisconsin, Madison, Wisconsin 53706
}

A B S T R A C T Patterns of bone loss in the axial and the appendicular skeleton were studied in 187 normal volunteers ( 105 women and 82 men; age range, 20$89 \mathrm{yr})$ and in 76 women and 9 men with vertebral fractures due to osteoporosis. Bone mineral density was measured in vivo at the lumbar spine (predominantly trabecular bone) by dual photon absorptiometry and at the midradius ( $>95 \%$ cortical bone) and distal radius (75\% cortical and $25 \%$ trabecular bone) by single photon absorptiometry. In normal women, bone diminution from the vertebrae began in young adulthood and was linear. In the appendicular skeleton, bone diminution did not occur until age $50 \mathrm{yr}$, was accelerated from ages 51 to $65 \mathrm{yr}$, and then decelerated somewhat after age $65 \mathrm{yr}$. Overall bone diminution throughout life was $47 \%$ for the vertebrae, $30 \%$ for the midradius, and $39 \%$ for the distal radius. In normal men, vertebral and appendicular bone diminution with aging was minimal or insignificant. Mean bone mineral density was lower in patients with osteoporosis than in age- and sex-matched normal subjects at all three scanning sites, although spinal measurements discriminated best; however, there was considerable overlap. By age $65 \mathrm{yr}$, half of the normal women (and by age $85 \mathrm{yr}$, virtually all of them) had vertebral bone mineral density values below the 90th percentile of women with vertebral fractures and, thus, might be considered to have asymptomatic osteoporosis. For men, the degree of overlap was less. The data suggest that disproportionate loss of trabecular bone from the axial skeleton is a distinguishing characteristic of spinal osteoporosis.

Address reprint requests to Dr. Riggs.

Received for publication 28 May 1980 and in revised form 29 September 1980.

\section{INTRODUCTION}

The clinical syndrome of spinal osteoporosis is characterized by the occurrence of nontraumatic vertebral fractures. The disease occurs mainly in women and elderly persons. The observation that bone mass in the general population decreases with age has led to the suggestion that osteoporosis represents an extreme form of the normal aging process (1). Breaking strength of bone is linearly related to its mineral content; hence, measurements of bone mineral content (BMC) ${ }^{1}$ at the actual sites of fracture should be the most accurate method of determining fracture risk $(2,3)$. In recent years, several methods of quantifying BMC of the appendicular skeleton have been developed (4). These measurements, however, have not provided good discrimination between subjects with spinal osteoporosis and age- and sex-matched controls (5-7). Because appendicular bone is predominantly cortical, whereas the vertebrae are predominantly trabecular, Nordin (6), and Mazess (4), and we (7) have hypothesized that subjects with spinal osteoporosis have lost disproportionately large amounts of trabecular bone. The present study tests this hypothesis.

Bone diminution with aging was assessed by measuring bone mineral density (BMD) concurrently at sites in the axial and the appendicular skeleton. BMD of the vertebrae (which consists mostly of trabecular bone) was determined by our modification (8) of the new technique of dual photon absorptiometry $(9,10)$. BMD of the midradius ( $>90 \%$ cortical bone) and the distal radius (75\% cortical and $25 \%$ trabecular bone) was measured by single photon absorptiometry $(7,11)$.

\footnotetext{
${ }^{1}$ Abbreviations used in this paper: BMC, bone mineral content; BMD, bone mineral density.
} 


\section{METHODS}

Normal subjects and patients. 187 normal volunteers (105 women and 82 men) had bone mineral measurements. Their ages ranged from 20 to $89 \mathrm{yr}$. All normal subjects were volunteers and gave their informed consent. They were ambulatory, in good health, and not on any medical therapy. None had a previous history of back pain or fractures, and roentgenograms of the spinal column showed no evidence of vertebral fractures or severe osteoarthritis. 85 patients (76 women and 9 men) with primary osteoporosis were also studied. Their mean age was $67.3 \mathrm{yr}$ (range, $50-85 \mathrm{yr}$ ). Other than fulfilling the criteria listed below, they formed an unselected sample of patients with osteoporosis who had been referred to the Metabolic Bone Disease Clinic at the Mayo Clinic. Each patient had generalized radiolucency on spinal roentgenograms, and one or more vertebral compression fractures that had occurred spontaneously or after minor incidents such as bending or coughing. They were ambulatory, in good health except for osteoporosis, and had no recognizable disease or history of use of drugs known to produce abnormalities in calcium metabolism.

Bone densitometry. BMD of the axial skeleton was determined by dual photon absorptiometry, as described by Mazess et al. $(9,10)$ for measuring total skeletal mineral content and adapted to a restricted scanning field by Wilson and Madsen (12). The dual photon absorption technique for measuring bone mineral content is based on measurements of radiation transmission of two separate photon energies through a medium consisting of two different materials, bone and soft tissue. The dichromatic beam from a ${ }^{153} \mathrm{Gd}$ source has photon electric peaks at $\sim 44$ and $100 \mathrm{keV}$.

We have modified the previous technique by using a smaller beam and by adding an edge-detection subprogram. Because of the improved precision and resolution from this modification, we can recognize anatomic details of the lumbar spine. The instrument consists of an Ohio Nuclear dual probe scanner frame with high-precision scanning mechanics, a $1.5 \mathrm{Ci}{ }^{153} \mathrm{Gd}$ source, and a collimated $\mathrm{NaI}$ detector (OhioNuclear Inc., subsidiary of Technicare Corp., Solon, Ohio). The collimated photon beam (6-mm Diam) traverses a $20-\mathrm{cm}$ path across the spine in the area of interest and measurements are taken each second (the equivalent of one measurement every $1.2 \mathrm{~mm}$ ). The distance between scanning paths is $5 \mathrm{~mm}$. The scanner is interfaced with a PDP-11/V03 computer that also controls scanning pattern, speed, and data acquisition. The computer algorithm performs point-by-point determination of density of bone mineral, and an edge-detection program recognizes bone edges by evaluating the relative change in mineral density values between points. Crossover (from the 100 to the $44-\mathrm{keV}$ channel, 4-6\% depending on the source) and dead-time corrections $(2.1 \mu \mathrm{m} / \mathrm{s})$ are made. The values are derived experimentally. Programs have been developed for point-by-point calculation and display of bone mineral. In addition, programs were developed for monitoring speed and hardware performance.

Data are accumulated on disks and processed by a Data General NOVA XII/20 computer (MDS, Modumed system, Data General Corp., Westboro, Mass.). Intensity-modulated images of the spine are displayed on a $64 \times 64$ matrix with 16 gray levels. Lightpen interaction allows determination of the area of interest for immediate comparison of different parts of the skeleton. BMC of the spine was assessed from scans of the L-1 to L-4 region. BMD, expressed in grams per square centimeter, was derived by dividing BMC by the projected area of the spine. This value included vertebral bodies and disk interspaces. With this method, individual vertebrae were recognized in all of the normal volunteers and in $\sim 60 \%$ of the patients with osteoporosis. Even when individual vertebrae cannot be completely resolved, the L-1 to $\mathrm{L}-4$ scanning area can be separated from the remainder of the spine by its relationship to other anatomic markers on the image. T-12 can be recognized by the presence of floating ribs, and L-5 can be identified by its proximity to the sacrum. In contrast to random sampling procedures, a standard area of bone is measured (even though the lumbar vertebra may be compressed, only the L-1 to L-4 area is measured) by our approach. For assessing the reproducibility of the measurements of the lumbar spine, a total of 25 measurements were made on five volunteers during a period of $10 \mathrm{mo}$. The average coefficient of variation was $2.3 \%$.

Measurements of bone density were also made at the midradius and at the distal radius with use of the single photon absorptiometric technique, as described by Cameron and Sorenson (11). This method utilizes a monochromatic beam from ${ }^{125}$ I source. The forearm is wrapped in tissue-equivalent material and is transversely scanned to give a constant thickness. The forearm is scanned by driving the rigidly linked isotope source and $\mathrm{NaI}$ detector across it at a right angle to its axis. Three linear scans are made at each site, and the results are averaged. Specific scanning sites are the midradius and the distal radius ( $10 \%$ of the radius length) of the nondominant arm. The amount of bone mineral is inversely related to the integrated transmission-count rate across the bone. Bone width and mineral content per unit length of bone (gram per centimeter) can be obtained by simple calibration procedures. In our laboratory, replicate scans made on the same persons at different times had a coefficient of variation of $3 \%$ for the midradius and of 3 to $5 \%$ for the distal radius (7).

Statistical methods. The regression of bone mineral measurements on age was approached in two ways. First, separate linear regressions were performed for ages 20 to 50 and 51 to $65, \geq 51$ and $\geq 66$ years, respectively. The results of linear regression in the various age groups were compared for assessment of consistency of the relationship with age. For the second approach, evidence of a curvilinear relationship with age was assessed by successively fitting linear, parabolic, cubic, and quartic polynomial regressions on age. The significance of the regression coefficients was then evaluated.

Normalizing variables to be used in defining the "normal limits" were evaluated in each sex by multiple linear regression analysis using the model $Y=a+b_{1} x_{1}+b_{2} x_{2}$, etc. The significance of several independent variables in relation to the dependent variable of vertebral mineral content was assessed by standard statistical methodology for multiple linear regression.

For establishing normal limits, the lower 5th percentile of the residuals $(\mathrm{L})$ from the appropriate regression equation was estimated nonparametrically as $L=(1-G) \times R_{J}+G$ $\times R_{J+1}$, in which $N$ is the sample size, $J$ is the integer part of $N \times 0.05, \mathrm{G}$ is the fractional part of $N \times 0.05, \mathrm{R}_{\mathrm{J}}$ is the $\mathrm{J}^{\text {th }}$ smallest residual (observed minus predicted), and $R_{\mathrm{J}+1}$ is the $(\mathrm{J}+1)^{\text {st }}$ smallest residual. The residuals are ordered smallest (most negative) to largest (most positive).

\section{RESULTS}

Normalization of data. The effect of the independent variables of age, projected area of the scan, height, weight, and body surface area on the dependent area of vertebral mineral content for the normal subjects is given in Table I. The variable with the greatest 
TABLE I

Assessment of Independent Variables in Establishing Normal Limits for BMC of the Vertebrae (Dependent Variable) in Normal Subjects

\begin{tabular}{|c|c|c|c|c|}
\hline \multirow[b]{2}{*}{ Independent variable } & \multicolumn{2}{|c|}{ Normal women* } & \multicolumn{2}{|c|}{ Normal ment } \\
\hline & $\mathrm{S}_{\boldsymbol{y} \cdot \boldsymbol{x}}$ & $P$ value & $\mathrm{S}_{y \cdot x}$ & $P$ value \\
\hline & $g$ & & $g$ & \\
\hline Age, $y r$ & 10.07 & $<0.001 \S$ & 14.36 & $0.023 \S$ \\
\hline Scan area, $\mathrm{cm}^{2}$ & 11.10 & $<0.001 \S$ & 8.96 & $<0.001 \S$ \\
\hline Age and scan area & 7.67 & $<0.0019$ & 8.82 & $<0.0019$ \\
\hline Height, $\mathrm{cm}$ & 7.36 & $0.002 * *$ & 8.79 & NS** \\
\hline Weight, $k g$ & 7.13 & $<0.001^{* *}$ & 8.57 & $0.021 * *$ \\
\hline Body surface & & & & \\
\hline area, $m^{2}$ & 7.06 & $<0.001^{* *}$ & 8.55 & $0.019^{* *}$ \\
\hline
\end{tabular}

$S_{y}$ is the overall standard deviation in BMC. $S_{y \cdot x}$ is the residual $\mathrm{SD}$ in the $\mathrm{BMC}$ about the fitted regression equation. * $S_{y}, 14.06$.

$\ddagger S_{y}, \mathbf{1 4 . 7 5}$.

$\S$ Two-tail $P$ value resulting from testing the significance of this variable when considered singly.

I Two-tail $P$ value resulting from testing the significance of age and scan area when considered simultaneously. For women, scan area added significantly to age $(P<0.001)$. For men, however, age did not add significantly to scan area, whereas scan area did add significantly to age $(P<0.001)$.

** Two-tail $P$ value resulting from testing the significance of this variable in comparison to the equation where age and scan area were considered simultaneously.

effect in both sexes was age. The two variables of age and the projected area of the scan (which corrects for the differences in size of the vertebrae) accounted for $71 \%$ of the variation about the mean in women and $65 \%$ in men. Because these are the two variables used to define normal limits in men, it is equivocal whether an age correlation is needed. The addition of height was not significant in men, although it resulted in a small but statistically significant improvement in women. Body weight and body surface area resulted in small but significant decreases in residual variance in both sexes.

Normal subjects. In women, bone diminution with aging occurred at all three scanning sites. The age regression of BMD from the spine was linear and occurred at a rate of $0.0092 \mathrm{~g} / \mathrm{cm}^{2}$ per yr (Fig. 1). Overall, the predicted mean at age $90 \mathrm{yr}$ was $47 \%$ less than the predicted mean at age $20 \mathrm{yr}$ (Fig. 1). Regression analysis by either method (see Statistical methods) supported a simple linear function for all ages. No evidence of curvilinearity or of a more negative slope during the postmenopausal interval of 51-65 yr was detected. The possible effect of the menopause on acceleration of diminution in vertebral BMD was investigated further by correcting for variability in the age at onset of menopause in the postmenopausal

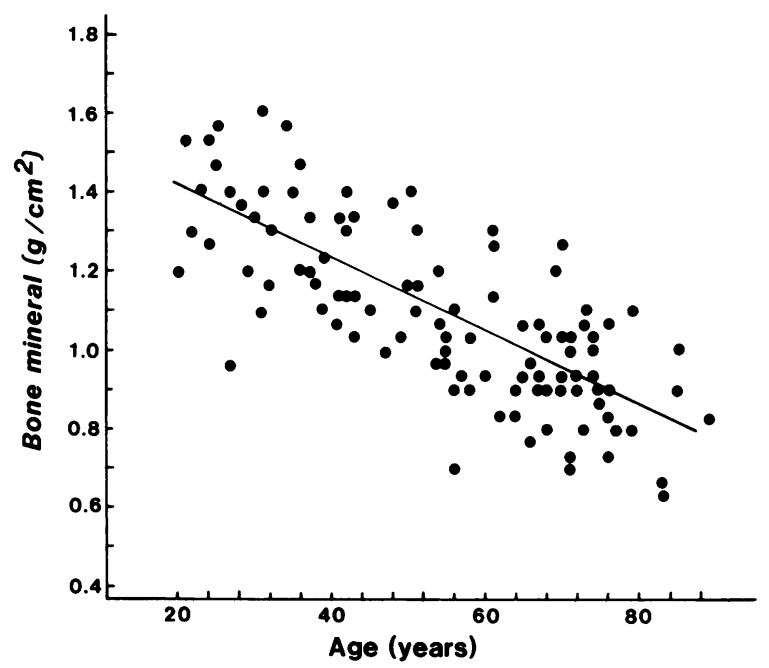

FIGURE 1 Regression of BMD of lumbar spine on age in 105 normal women (๑). Equation for regression, $y=1.59-0.0092$ age.

subjects. For this analysis, premenopausal subjects were assigned their actual age while postmenopausal subjects were assigned an age corresponding to age $50 \mathrm{yr}$ (the usual age of menopause) plus the number of years since menopause. No increase in the diminution rate of vertebral BMD could be demonstrated postmenopausally (Table II). The age regression for BMD from the midradius and the distal radius was best described with cubic equations. Separate analysis for each of the various age groups showed that significant bone loss at either of these sites did not occur until after age $50 \mathrm{yr}$. From ages 51 to $65 \mathrm{yr}$, BMD diminished at a rate of 0.0118 and $0.0108 \mathrm{~g} / \mathrm{cm}$ per yr for the midradius and the distal radius, respectively; after age $65 \mathrm{yr}$, the diminution rate was less (Table III). The predicted mean at age $90 \mathrm{yr}$ for the midradius and distal radius was 30 and $39 \%$, respectively, less than the predicted mean in young adult life. The linear

TABLE II

Vertebral BMD in Relation to Menopause in Normal Women by Linear Regression Analysis*

\begin{tabular}{lccc}
\hline \multicolumn{1}{c}{ Menoage } & $\mathrm{A}$ & $\mathrm{B}$ & $\mathrm{S}_{y \cdot x}$ \\
\hline \multicolumn{1}{c}{$y r$} & & & \\
& & & \\
Overall & 1.5364 & $-0.0080 \ddagger$ & 0.1640 \\
$20-50$ (premenopausal) & 1.5596 & $-0.0077 \S$ & 0.1495 \\
$51+$ (postmenopausal) & 1.2705 & $-0.0043 \S$ & 0.1645
\end{tabular}

${ }^{*} y=\mathrm{A}+\mathrm{B} \cdot$ Menoage (yr). Menoage, actual age if premenopausal and $50+$ number of years postmenopausal if postmenopausal. The pre- and postmenopausal slopes were not significantly different.

$\$$ Slope significantly different from zero, $P<0.001$

$\$$ Slope significantly different from zero, $P<0.05$. 
TABLE III

Parameters of Linear Regression of Bone Variables on Age in Normal Females

\begin{tabular}{lrccc}
\hline & $\mathrm{N}$ & $\mathrm{A}$ & $\mathrm{B}$ & $\mathrm{S}_{\mathrm{y} \cdot \mathrm{r}}$ \\
\hline Lumbar spine, $\mathrm{g} / \mathrm{cm}^{2}$ & & & & \\
$\quad$ Overall & 105 & 1.5898 & $-0.0092^{*}$ & 0.1468 \\
$20-50 \mathrm{yr}$ & 42 & 1.5706 & $-0.0083^{*}$ & 0.1549 \\
$51+\mathrm{yr}$ & 63 & 1.4146 & $-0.0067^{*}$ & 0.1412 \\
$51-65 \mathrm{yr}$ & 24 & 1.5958 & -0.0099 & 0.1523 \\
$66+\mathrm{yr}$ & 39 & 1.4339 & -0.0069 & 0.1375 \\
Midradius, g/cm & & & & \\
Overall & 105 & 1.2041 & $-0.0056^{*}$ & 0.1124 \\
$20-50 \mathrm{yr}$ & 42 & 0.9328 & 0.0025 & 0.0885 \\
$51+\mathrm{yr}$ & 63 & 1.2793 & $-0.0068^{*}$ & 0.1123 \\
$51-65 \mathrm{yr}$ & 24 & 1.5602 & $-0.0118 \ddagger$ & 0.1130 \\
$66+\mathrm{yr}$ & 39 & 1.2669 & $-0.0066 \ddagger$ & 0.1135 \\
Distal radius, g/cm & & & & \\
Overall & 105 & 1.1949 & $-0.0065^{*}$ & 0.1237 \\
$20-50 \mathrm{yr}$ & 42 & 0.9638 & 0.0004 & 0.1012 \\
$51+\mathrm{yr}$ & 63 & 1.3012 & $-0.0081^{*}$ & 0.1284 \\
$51-65 \mathrm{yr}$ & 24 & 1.4449 & -0.0108 & 0.1139 \\
$66+\mathrm{yr}$ & 39 & 1.4398 & $-0.0099 \ddagger$ & 0.1385 \\
\end{tabular}

$y=A+B \cdot a g e(y r)$. Slope significantly different from zero.

${ }^{*} P<0.001$.

$\ddagger P<0.05$.

regression analysis of BMD for the various groups shown in Table III also indicated that a single linear regression was inadequate to describe the relationship for all ages. The slopes for the 20 - to 50 -yr-old women were slightly positive and not significantly different from zero, whereas the slopes for women $\geq 51 \mathrm{yr}$ old were negative and were significantly less than zero. The continuous cubic function was chosen for lower normal limits for the midradius and the distal radius in women because the fit was at least as good as that obtained by using separate regressions for the age groups and it was continuous. The regression lines for separate age groups were noncontinuous with each other. Although these separate regression lines could be statistically forced to meet at the common age points ( 50 and $65 \mathrm{yr}$ ), the choice of these ages was not unique, and seemed more arbitrary and less appropriate than a continuous function such as cubic regression.

When we related the total bone mineral (in grams) of the spine, including interspaces to age, we found a linear relationship similar to that for BMD. There was no evidence of curvilinearity or of a more negative slope during the postmenopausal interval of 51 to 65 yr. However, using total bone mineral, $37.5 \%$ of the osteoporotic women fell below the fifth percentile of normals as opposed to $44.7 \%$ when using BMD. Thus, we elected to express our data as BMD values.

Bone diminution was less in men (Table IV) than in women. The decline in BMD was linear (Fig. 2) for the vertebrae $\left(0.0021 \mathrm{~g} / \mathrm{cm}^{2}\right.$ per yr) and for the distal
TABLE IV

Parameters of Linear Regression of Bone Variables on Age in Normal Males

\begin{tabular}{lcccc}
\hline & $N$ & $\mathrm{~A}$ & $\mathrm{~B}$ & $\mathrm{~S}_{\mathrm{y} \cdot \mathrm{r}}$ \\
\hline Lumbar spine, $\mathrm{g} / \mathrm{cm}^{2}$ & & & & \\
$\quad$ Overall & 82 & 1.3299 & $-0.0021^{*}$ & 0.1595 \\
$20-50 \mathrm{yr}$ & 39 & 1.4076 & -0.0044 & 0.1761 \\
$51+\mathrm{yr}$ & 43 & 1.2531 & -0.0010 & 0.1456 \\
$51-65 \mathrm{yr}$ & 17 & 1.9535 & -0.0133 & 0.1543 \\
$\quad 66+\mathrm{yr}$ & 26 & 1.0450 & 0.0018 & 0.1382 \\
Midradius, g/cm & & & & \\
$\quad$ Overall & 82 & 1.3359 & -0.0005 & 0.1602 \\
$20-50 \mathrm{yr}$ & 39 & 1.2467 & 0.0023 & 0.1476 \\
$51+\mathrm{yr}$ & 43 & 1.3755 & -0.0011 & 0.1730 \\
$51-65 \mathrm{yr}$ & 17 & 1.7870 & -0.0084 & 0.1940 \\
$66+\mathrm{yr}$ & 26 & 1.3944 & -0.0013 & 0.1639 \\
Distal radius, $\mathrm{g} / \mathrm{cm}$ & & & & \\
Overall & 82 & 1.4495 & $-0.0032^{*}$ & 0.1727 \\
$20-50 \mathrm{yr}$ & 39 & 1.3071 & 0.0011 & 0.1687 \\
$51+\mathrm{yr}$ & 43 & 1.6110 & $-0.0055^{*}$ & 0.1758 \\
$51-65 \mathrm{yr}$ & 17 & 1.5093 & -0.0035 & 0.1533 \\
$66+\mathrm{yr}$ & 26 & 1.3391 & -0.0020 & 0.1933 \\
\hline
\end{tabular}

$y=\mathrm{A}+\mathrm{B} \cdot \operatorname{age}(\mathrm{yr})$.

* Slope significantly different from zero, $P<0.05$.

radius $(0.0032 \mathrm{~g} / \mathrm{cm}$ per $\mathrm{yr})$; it was insignificant for the midradius (Table IV).

Patients with osteoporosis. Compared with agecomparable normal subjects, patients with osteoporosis had significantly lower mean values at all three scanning sites (Table V). For women, the relative decrease was significantly more for the lumbar spine (19.6\%) than for the midradius $(8.4 \%)$ or the distal radius $(7.2 \%)$. Also, the proportion of female patients with osteoporosis who had values below the 5 th percentile for normal was significantly $(P<0.001)$ larger for the

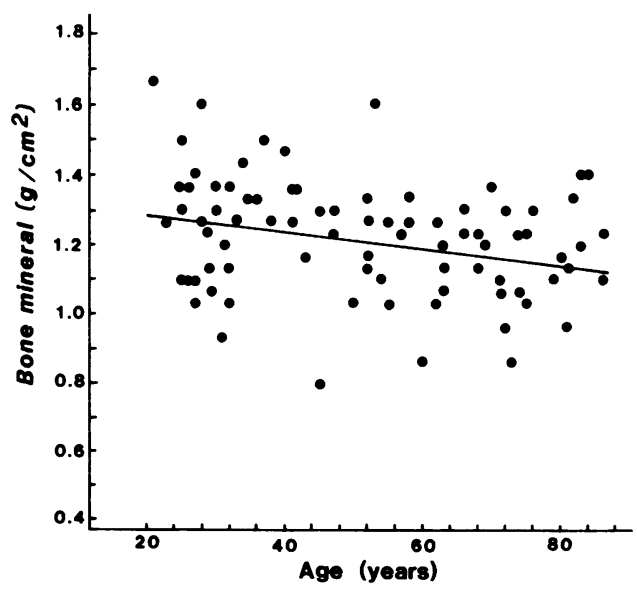

FIGURE 2 Regression of BMD of lumbar spine on age in 82 normal men (๑). Equation for regression, $y=1.33-0.0021$ age. 
TABLE V

Comparison of BMD in Normal and Osteoporotic Females of Comparable Ages

\begin{tabular}{ccccc}
\hline & & & \multicolumn{2}{c}{$\begin{array}{c}\text { Significance of } \\
\text { difference }\end{array}$} \\
\cline { 4 - 6 } $\begin{array}{c}\text { Measurement } \\
\text { site }\end{array}$ & Normals* & Osteoporotics $¥$ & $t$ & $P$ \\
\hline $\begin{array}{c}\text { Lumbar } \\
\text { spine, } \\
\text { g/cm }{ }^{2}\end{array}$ & $0.963 \pm 0.153$ & $0.777 \pm 0.137$ & 7.56 & $<0.001$ \\
$\begin{array}{c}\text { Midradius, } \\
\text { g/cm }\end{array}$ & $0.819 \pm 0.128$ & $0.750 \pm 0.121$ & 3.26 & $<0.001$ \\
$\begin{array}{c}\text { Distal } \\
\text { radius, } \\
\text { g/cm }\end{array}$ & $0.754 \pm 0.148$ & $0.700 \pm 0.128$ & 2.31 & $<0.05$ \\
\hline
\end{tabular}

Values are for mean $\pm \mathrm{SD}$.

$* n=62$.

$\$ n=76$.

lumbar spine $(44.7 \%)$ than for the midradius (17.1\%) or the distal radius (6.6\%) (Figs. 3-5). For the smaller number of male patients with osteoporosis, results were similar (Figs. 6-8).

The 90th percentile (determined nonparametrically) for vertebral BMD found in this series of patients with osteoporosis and vertebral fractures, both male and female, was $0.965 \mathrm{~g} / \mathrm{cm}^{2}$ (Figs. 3 and 6). By age $65 \mathrm{yr}$, half of the normal women (and by age $85 \mathrm{yr}$, virtually all of them) had vertebral BMD measurements of less than this value (Fig. 1). For normal men, the degree of overlap was much less (Fig. 2).

\section{DISCUSSION}

We found important quantitative and qualitative differences in the pattern of bone diminution with

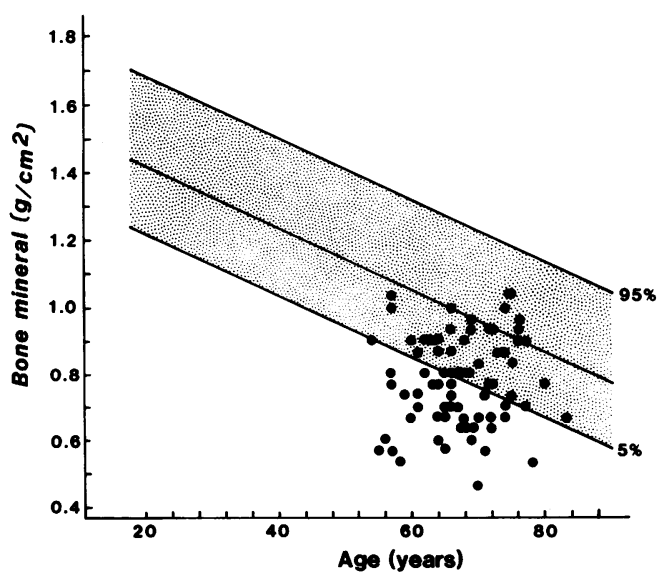

Figure 3 Individual values for BMD of lumbar spine in $\mathbf{7 6}$ women with osteoporosis and one or more vertebral-compression fractures (๑). Center line denotes age regression for normal women and upper and lower lines represent $90 \%$ confidence limits.

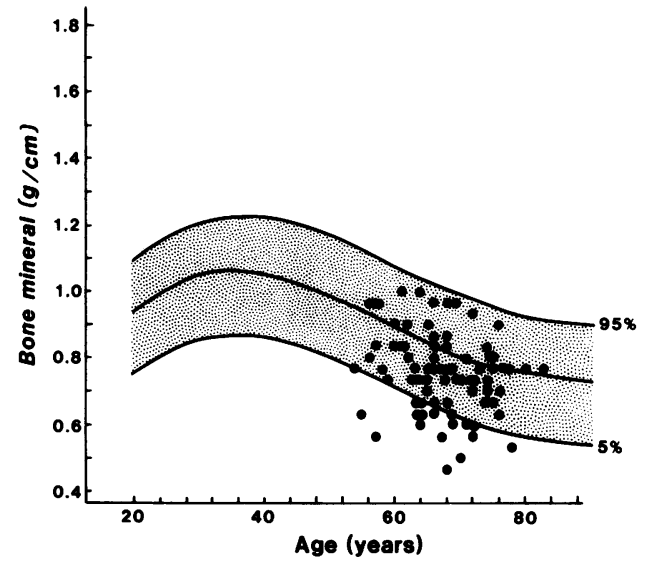

Figure 4 Individual values for BMD of midradius in $\mathbf{7 6}$ women with osteoporosis and one or more vertebral-compression fractures (O). Center line denotes age regression for normal women, and upper and lower lines represent $90 \%$ confidence limits. Age regression in normal women was best fit by the cubic equation, $y=0.342+0.046$ age -0.00093 age $^{2}+5.176 \cdot 10^{-6}$ age $^{3}$.

aging from the appendicular and the axial skeleton and, by inference, from cortical and trabecular bone, when both were evaluated in the same patients. Although we believe that these differences have resulted from age-related bone loss, we cannot completely exclude the possibility of a secular effect on bone that may have occurred in the $70 \mathrm{yr}$ separating the youngest and oldest volunteers in our sample. Smith et al. (13), however, who studied bone loss with age at the midradius and distal radius using single photon absorptiometry, found that rates of bone

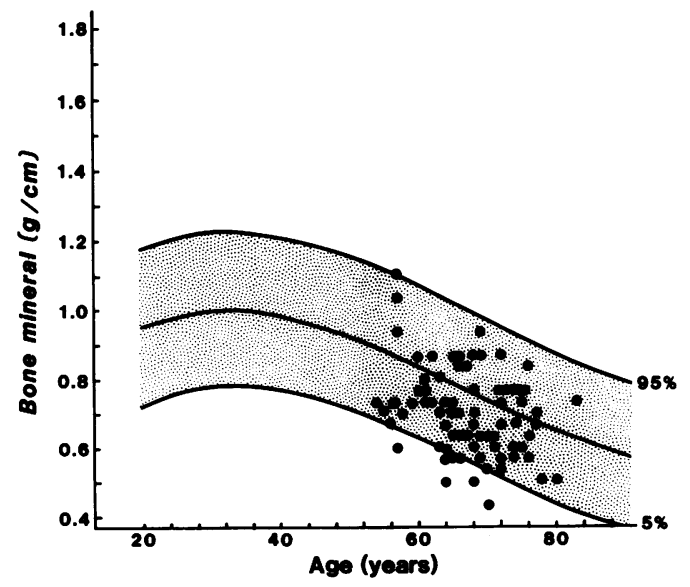

FIGURE 5 Individual values for BMD of distal radius in $\mathbf{7 6}$ women with osteoporosis and one or more vertebral-compression fractures (O). Center line denotes age regression for normal women, and upper and lower lines represent $90 \%$ confidence limits. Age regression in normal women was best fit by the cubic equation, $y=0.576+0.0289$ age -0.000594 age $^{2}+3.053 \cdot 10^{-6}$ age $^{3}$. 


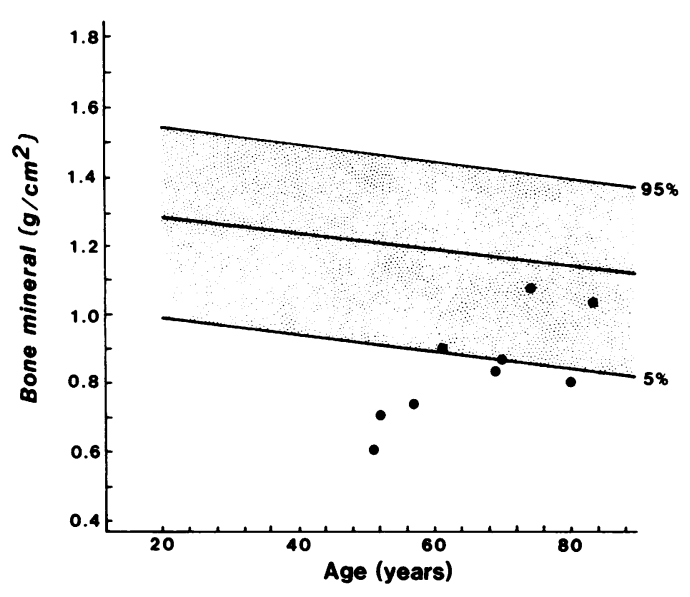

FIgURE 6 Individual values for BMD of lumbar spine in nine men with osteoporosis and one or more vertebralcompression fractures (O). Center line denotes age regression for normal men, and upper and lower lines represent $90 \%$ confidence limits.

diminution calculated from cross-sectional and longitudinal measurements in the same subjects were virtually identical.

In agreement with published studies (1, 5-7, 13-17), we found that women had little or no bone diminution from the appendicular skeleton until after age $50 \mathrm{yr}$. Bone diminution accelerated from ages 51 to $65 \mathrm{yr}$ and then decelerated somewhat after age $65 \mathrm{yr}$. In contrast to findings in the appendicular skeleton, bone diminution from the vertebrae began in young adulthood and continued linearly throughout life. In men, bone diminution from the lumbar spine and distal radius was minimal, from the midradius it was insignificant.

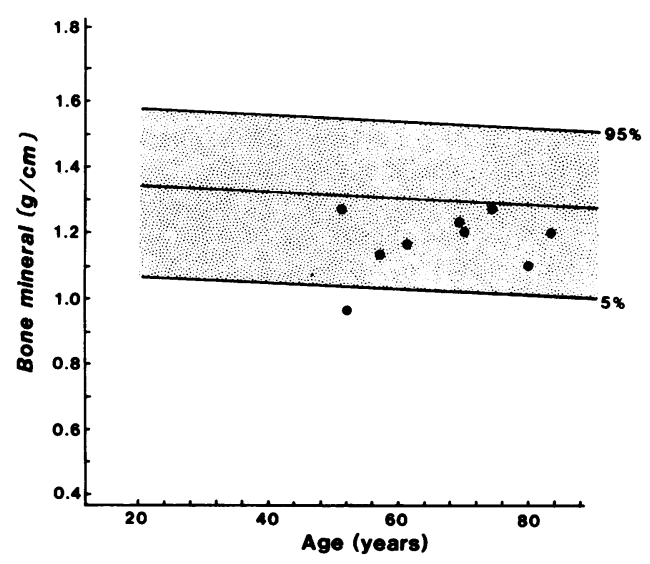

FIGURE 7 Individual values for BMD of midradius in nine men with osteoporosis and one or more vertebral-compression fractures (O). Center line denotes age regression for normal men, and upper and lower lines represent $90 \%$ confidence limits. Equation for age regression, $y=1.336$ -0.0005 age.

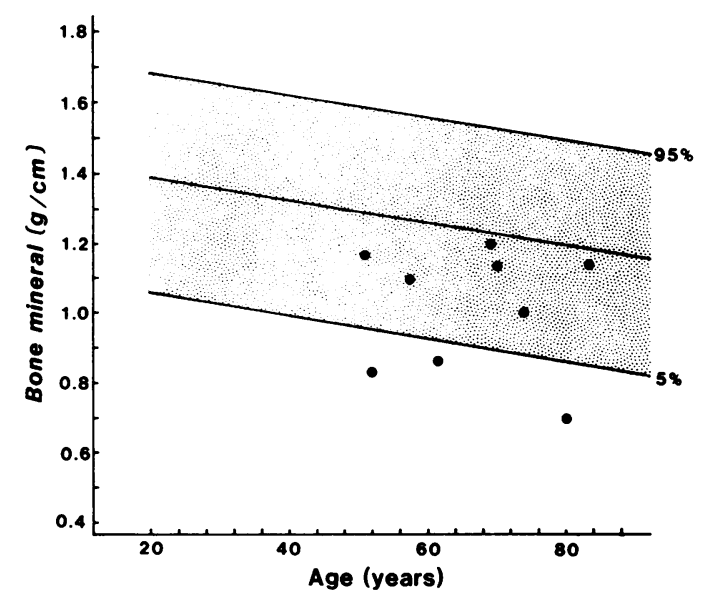

FIgURE 8 Individual values for BMD of distal radius in nine men with osteoporosis and one or more vertebral-compression fractures ( ). Center line denotes age regression for normal men, and upper and lower lines represent $90 \%$ confidence limits. Equation for age regression, $y=1.45-0.0032$ age.

We found that the cumulative diminution of BMD from the vertebrae between young adulthood and extreme old age was $47 \%$ for women and $14 \%$ for men. The overall diminution in women was similar to the value of $43 \%$ found by Meunier et al. (18), who studied diminution of trabecular bone mass in iliac-crest biopsy samples (obtained from normal persons who had died suddenly); in men, however, it was less than the value of $27 \%$ that they found. Additionally, the rate of bone diminution with age that we found was threefold greater than was found in a smaller series reported by Madsen (19), who also used dual photon absorptiometry in vivo. The reason for this discrepancy is unclear.

Several recent densitometric studies have provided strong evidence that the midlife acceleration of appendicular bone loss in women can be directly related to postmenopausal estrogen deficiency $(20-22)$. For the radius, we have confirmed a temporal relationship in women between accelerated bone loss and the usual age at onset of menopause; however, for the spine, we could not demonstrate this relationship. Meunier et al. (18) measured trabecular bone mass in iliac biopsy specimens from 236 control subjects who had suffered sudden or accidental deaths. In agreement with our results, they found a linear decrease in trabecular bone mass with an increase in age in premenopausal females. They also, however, reported an acceleration (about $10 \%$ over predicted) of the linear diminution of trabecular bone as age increased in the postmenopausal period. Thus, cortical bone loss from the appendicular skeleton may be more clearly related to estrogen deficiency than is trabecular bone loss from the axial skeleton. In contrast, Dalen et al. (23) reported that premenopausal subjects who had undergone oophorectomy for treatment of breast cancer had 
apparently lost more trabecular than cortical bone. The effect of the menopause on the rate of bone loss in the vertebrae relative to that in the appendicular skeleton must be studied further. A systematic longitudinal study should ideally include vertebral BMD measurements made in perimenopausal women followed transmenopausally.

The present study permits a definition of spinal osteoporosis in terms of vertebral BMD rather than, as has been the practice, in terms of the presence of nontraumatic vertebral fractures. The 90th percentile for vertebral BMD for patients with nontraumatic vertebral fractures was $0.965 \mathrm{~g} / \mathrm{cm}^{2}$. Thus, we have chosen this value to define the threshold below which the risk for nontraumatic vertebral fractures increases. The incidence of asymptomatic osteoporosis was assessed by relating the age-specific distribution of BMD values in the normal female population to this threshold. By age $65 \mathrm{yr}$, half of the women (and by age $85 \mathrm{yr}$, virtually all of them) have BMD values below the threshold for fracture. Thus, the incidence of asymptomatic spinal osteoporosis appears to be much greater than has been suspected.

Beginning with the report by Albright et al. (24), excessive bone loss was considered to be the principal determinant of osteoporosis. Newton-John and Morgan (1), however, hypothesized that age-related bone loss is constant in all persons and that the principal determinant of osteoporosis is the amount of bone present at skeletal maturity. These two models obviously are not mutually exclusive, and either hypothesis alone probably provides an inadequate description of the pathogenesis. In a longitudinal study, Smith et al. (13), for example, found that the age-related loss of appendicular bone was an exponential function of bone mass; those with the most bone also had the most rapid bone loss.

Despite these reservations, several of our findings in women do indeed support Newton-John and Morgan's concept (1) that a relatively low vertebral BMD in young adulthood is an independent risk factor for a relatively low vertebral BMD in later life. Thus, in women, the lower limit of the distribution of vertebral BMD in young adults was only $1 \mathrm{SD}$ above the fracture threshold; the mean rate of diminution was $1 \mathrm{SD} / 17 \mathrm{yr}$; there was a unimodal distribution of BMD at any fixed age; and, as age-related bone diminution ensued, progressively more of the normal population had BMD values below the threshold for fracture and had overlapping values with patients with nontraumatic vertebral fractures.

We also provide evidence, however, that the Newton-John and Morgan model (1) is more applicable to cortical than to trabecular bone diminution. For the midradius (which consists of predominantly cortical bone), mean BMD was only slightly less for patients with osteoporosis than for age-comparable normal subjects. For the lumbar spine (which consists of predominantly trabecular bone), BMD for patients with spinal osteoporosis was much lower than normal. Thus, women with and without spinal osteoporosis lose substantial but similar amounts of cortical bone, but those with spinal osteoporosis lose more trabecular bone.

Men had a different pattern of bone diminution with age; it was less than that recorded for women at all three scanning sites, and for the midradius it was insignificant. There was also less overlap between normal subjects and patients with vertebral fractures.

The demonstration of qualitative and quantitative differences in trabecular and cortical bone diminution in elderly normal subjects and in patients with spinal osteoporosis has both theoretical and practical implications. Theoretically, these results fail to support the widely held assumption that rates of bone loss in different portions of the skeleton are similar. Instead, they suggest that cortical bone and trabecular bone function as separate compartments, which differ in respect to onset and rate of bone loss and, possibly, also in respect to homeostatic regulation. Practically, they show that direct spinal measurements of bone density are greatly superior to appendicular measurements for evaluating the severity of spinal osteoporosis.

\section{REFERENCES}

1. Newton-John, H. F., and D. B. Morgan. 1968. Osteoporosis: disease or senescence? Lancet. I: 232-233.

2. Chalmers, J., and J. K. Weaver. 1966. Cancellous bone: its strength and changes with aging and an evaluation of some methods for measuring its mineral content. $J$. Bone Jt. Surg. Am. Vol. 48A: 299-308.

3. Arnold, J. S. 1973. Amount and quality of trabecular bone in osteoporotic vertebral fractures. Clin. Endocrinol. Metab. 2: 221-238.

4. Mazess, R. B. 1979. Measurement of skeletal status by noninvasive methods. Calcif. Tissue Res. 28: 89-92.

5. Johnston, C. C., D. M. Smith, P. L. Yu, and W. P. Deiss, Jr. 1968. In vivo measurement of bone mass in the radius. Metab. Clin. Exp. 17: 1140-1153.

6. Nordin, B. E. C. 1971. Clinical significance and pathogenesis of osteoporosis. Br. Med. J. 1: 571-576.

7. Wahner, H. W., B. L. Riggs, and J. W. Beabout. 1977. Diagnosis of osteoporosis: usefulness of photon absorptiometry at the radius. J. Nucl: $\mathrm{Med}$. 18: 432-437.

8. Dunn, W. L., H. W. Wahner, and B. L. Riggs. 1980. Measurement of bone mineral content in human vertebrae and hip by dual photon absorptiometry. Radiology. 136: 485-487.

9. Mazess, R. B., M. Ort, P. Judy, and W. Mather. 1970. Absorptiometric bone mineral determination using ${ }^{153} \mathrm{Gd}$. In Proceedings, Bone Measurement Conference. J. R. Cameron, editor. U. S. Atomic Energy Commission Conference 700515 (available from Clearinghouse for Federal Scientific and Technical Information, Springfield, Va.). 308-312.

10. Mazess, R. B., J. Hanson, W. Kan, M. Madsen, N. Pelc, C. R. Wilson, and R. M. Witt. 1974. Progress in dual 
photon absorptiometry of bone. In Proceedings, Symposium on Bone Mineral Determinations. P. Schmeling, editor. Aktiebolaget Atomenergi Publication. Studsvik Sweden. 489: 40-52.

11. Cameron, J. R., and J. Sorenson. 1964. Measurement of bone mineral in vivo: an improved method. Science (Wash., D. C.). 142: 230-232.

12. Wilson, C. R., and M. Madsen. 1977. Dichromatic absorptiometry of vertebral bone mineral content. Invest. Radiol. 12: 180-184.

13. Smith, D. M., M. R. A. Khairi, J. Norton, and C. C. Johnston, Jr. 1976. Age and activity effects on rate of bone mineral loss. J. Clin. Invest. 58: 716-721.

14. Meema, H. E. 1966. Menopausal and aging changes in muscle mass and bone mineral content. J. Bone Jt. Surg. Am. Vol. 48A: 1138-1144.

15. Mazess, R. B., and J. R. Cameron. 1973. Bone mineral content in normal U. S. whites. In Proceedings of International Conference on Bone Mineral Measurements. R. B. Mazess, editor. U. S. Department of Health, Education, and Welfare. 228-238.

16. Goldsmith, N. F. 1973. Normative data from the osteoporosis prevalence survey, Oakland, California, 19691970. Bone mineral at the distal radius: variation with age, sex, skin color, and exposure to oral contraceptives and exogenous hormones; relation to aortic calcification, osteoporosis, and hearing loss. In Proceedings of International Conference on Bone Mineral Measurements. R. B. Mazess, editor. U. S. Department of Health, Education, and Welfare. 239-266.
17. Smith, D. M., M. R. A. Khairi, and C. C. Johnston. 1975. The loss of bone mineral with aging and its relationship to risk of fracture. J. Clin. Invest. 56: 311-318.

18. Meunier, P., P. Courpron, C. Edouard, J. Bernard, J. Bringuier, and G. Vignon. 1973. Physiological senile involution and pathological rarefaction of bone. Clin. Endocrinol. Metab. 2: 239-256.

19. Madsen, M. 1977. Vertebral and peripheral bone mineral content by photon absorptiometry. Invest. Radiol. 12: $185-188$.

20. Lindsay, R., J. M. Aitken, J. B. Anderson, D. M. Hart, E. B. MacDonald, and A. C. Clarke. 1976. Long-term prevention of postmenopausal osteoporosis by oestrogen: evidence for an increased bone mass after delayed onset of oestrogen treatment. Lancet. I: 1038-1041.

21. Horsman, A., B. E. C. Nordin, J. C. Gallagher, P. A. Kirby, R. M. Milner, and M. Simpson. 1977. Observations of sequential changes in bone mass in postmenopausal women: a controlled trial of oestrogen and calcium therapy. Calcif. Tissue Res. 22(S): 217-224.

22. Recker, R. R., P. D. Saville, and R. P. Heaney. 1977. Effect of estrogens and calcium carbonate on bone loss in postmenopausal women. Ann. Intern. Med. 87: 649-655.

23. Dalen, N., B. Lamke, and A. Wallgren. 1974. Bone-mineral losses in oophorectomized women. J. Bone Jt. Surg. Am. Vol. 56A: 1235-1238.

24. Albright, F., P. H. Smith, and A. M. Richardson. 1941. Postmenopausal osteoporosis.JAMA (J. Am. Med. Assoc.). 116: 2465-2474. 